Methods The study was carried out on 870 children less than 15 years who referred to Shahid Motahari burn hospital in Tehran from March 2007 to March 2009.

Results Mean age of the subjects was 4.2 years and $63.3 \%$ were male. Highest proportion of subjects (32.2\%) occurred in summer followed by winter and fall. The most frequent places were kitchen $(57.7 \%)$, living room $(17.4 \%)$ and yard $(10.2 \%)$. Scalds $(68.2 \%)$ constituted most of the cases, followed by flamerelated burns $(24.6 \%)$, electrical burns $(4.8 \%)$, contact burns and chemical burns. Inhalation injury was observed in $6.9 \%$ of the subjects. Mean body surface area (BSA) was $21.6 \%$ (SD: $16.5 \%$ ). About $80 \%$ of patients had third-degree burns. The incidence of death was $10.6 \%$ in all cases. Considering BSA, the risk of death was $0.0 \%$ (BSA<10\%), 0.4\% (BSA:10-19\%), $3.1 \%$ (BSA:20-29\%), 17.8\% (BSA:30-39\%), 38.8\% (BSA: 40-49\%) and $97.7 \%$ (BSA:50\% or more).

Discussion Promoting safety measures in home kitchens and cooking facilities is a priority for burn prevention. Intervention to improve burn care and treatment outcomes is urgently needed.

\title{
0731 HOSPITALISED BURN INJURIES IN 870 CHILDREN IN TEHRAN
}

H Karimi*, A Motabar, S A Motevalian* Correspondence: Burn Research Center, Iran University of Medical Sciences, Shahid Motahari Burn Hospital, Rashid Yasemi Street, Vali-Asr Street, Tehran, Iran

10.1136/ip.2010.029215.731

Introduction Burn injuries were the 13th cause of burden of disease in all age groups and the 7th cause in 5-14 years children in Iran in 2003. The objective of this study was to describe demographic and injury characteristics of burn injuries in a referral burn centre. 